\title{
Erratum to: Magnesium-based composites with improved in vitro surface biocompatibility
}

Zhiguang Huan • Sander Leeflang •

Jie Zhou · Jurek Duszczyk

Published online: 11 January 2011

(C) Springer Science+Business Media, LLC 2011

Erratum to: J Mater Sci: Mater Med (2010)

21:3163-3169

DOI 10.1007/s10856-010-4165-7

In the original version of this article the corresponding author unfortunately failed to list Sander Leeflang among the list of authors. The corrected author list is now given above.

The online version of the original article can be found under doi: 10.1007/s10856-010-4165-7.

Z. Huan $\cdot$ S. Leeflang $\cdot$ J. Zhou $(\bowtie) \cdot$ J. Duszczyk Department of Materials Science and Engineering, Delft University of Technology, Mekelweg 2, 2628 CD Delft, The Netherlands

e-mail: j.zhou@tudelft.nl 